\title{
DESAFIOS DOCENTES E AS FERRAMENTAS TECNOLÓGICAS NA NÃO PRESENSIALIDADE.
}

DOI: 10.37702/2175-957X.COBENGE.2021.3498

Fabio Raia - fabio.raia@mackenzie.br Universidade Prebiteriana Mackenzie RUA DOUTOR FELIPE FIGLIOLINI 183 04740-010 - São Paulo - SP

Resumo: A criatividade e a agilidade docente nesse período emergencial contaram com um auxílio fundamental, as plataformas de sistemas de aprendizagem, que foram e são responsáveis em manter o contato professor aluno minimamente ativo. Isso manteve a escola no "ar". No entanto, deve-se ressaltar, que a qualidade e robustez dessas atividades deve-se ao setor técnico-administrativo das instituições de ensino. $O$ presente trabalho apresenta uma coletânea e diversidade de ações tomadas por docentes, suas metodologias e técnicas para manter os conteúdos como estabelecidos em planos de ensino. A utilização de slides e compartilhamento de telas foi predominante e teve repercussão positiva entre os discentes. Os depoimentos e a coletânea de técnicas contaram com a participação de professores e alunos das áreas de ciclo básico e específico. Percebeu-se que a simplicidade do uso das técnicas sofisticadas prevaleceu durante o período de observação, que aconteceu entre 2020 até atual. o padrão síncrono foi adotado para as aulas teóricas e, quando permitido, aulas laboratoriais presenciais, caracterizando assim um ensino híbrido. Foram ouvidos $15 \%$ de docentes de um total de 130 e opiniões de 100 discentes em turmas de diferentes etapas de um mesmo curso.

Palavras-chave: Ensino híbrido, Atividades síncronas, Ensino remoto 


\section{DESAFIOS DOCENTES E AS FERRAMENTAS TECNOLÓGICAS NA NÃO PRESENSIALIDADE.}

\section{INTRODUÇÃO}

O modelo de ensino, no período de 2020 a 2021, foi modificado de forma abrupta e afetou a todos: instituição, alunos, docentes e servidores administrativos levando-os a uma realidade sem precedentes. Passou de um modelo presencial, para um modelo não presencial, previsto em lei Brasil 1 (2020) e sem as características do ensino à distância (previsto em lei) Brasil 2 (1996). O ensino híbrido vem sendo estudado e encontrou um case com a ocorrência da pandemia, Horn; Staker (2015), definem o ensino híbrido como um programa formal no qual um aluno aprende, em parte, por meio on-line, de forma supervisionada.

Para a atual situação não houve uma preparação ou treino, os docentes foram tomados de surpresa e buscaram soluções colecionando recursos e um novo tipo de aula surgiu, a aula síncrona. Cabe ressaltar que Oliveira, et. al (2013) fizeram uma caracterização tecnológica em situações como essa, na qual, estabeleceram a relação tecnológica entre professor - aluno - tecnologia, esse inter-relacionamento busca personalizar o ensino-aprendizagem. Esse conhecimento, no entanto, não estava planejado e não foi explorado em situações de simulação ou de teste. Ocorrendo uma busca desenfreada para solucionar um problema imediato.

O objetivo do presente trabalho é apresentar as soluções metodológicas e ferramentas mais utilizadas por docentes no exercício das aulas síncronas, durante o período de 2019 - 2020.

Como objetivo específico, mostra que soluções tomadas emergencialmente, podem remeter a epistemologia da educação, a um novo entendimento da aula presencial.

As soluções metodológicas irão comprometer o retorno do normal e novos costumes e procedimentos serão agregados à nova aula. $O$ aprendizado remoto síncrono, por exemplo, que é aquele que acontece em tempo real com interação em um lugar virtual específico em um horário definido, será opção mais próxima daquilo que representa uma aula, pois é realizado da mesma forma, como feito em uma sala de aula presencial.

Os métodos comuns de aprendizagem online síncrona incluem a videoconferência, teleconferência, chat (bate-papo) ao vivo e palestras, que são transmitidas ao vivo e vistas em tempo real. O público de palestras, que em passado não distante, estava limitado ao tamanho físico do ambiente, hoje se espalha e tem como limite a capacidade do ambiente virtual. Esse tipo de levar a informação ou formação, parece encontrar eco nos estudantes, tendo em vista a audiência em eventos, que no passado não tinham atrativo. Talvez o fator que mais influencia é a logística temporal, pois recebe-se o conteúdo em ambiente caseiro, com a grande vantagem de não necessitar de deslocamento até o local do evento. Podese dizer que o formato online síncrono é uma espécie de uma sala de aula portátil, ela está presente em seu smartfone, por exemplo. A sincronicidade permite uma exploração mais rápida dos conteúdos, tópicos e conceitos. Além disso, conta-se com o imediatismo. Sobre isso, Rushkoff (2019) comenta em possuir respostas imediatas e ações instantâneas. Reforçando a metodologia híbrida, que possibilita a troca de informações em grande velocidade. Por outro lado, deve-se pensar na solução híbrida, como argumentado por Brito (2020), que em ambientes presenciais e online são indissociáveis, e aquilo que define esse tipo de ensino são ações pedagógicas ligadas aos dois ambientes. O gerenciamento para esse tipo de aprendizagem é realizado pelos sistemas de educação à distância 
denominados de sistemas de gestão de aprendizagem (LMS). O moodle é um sistema desse tipo e, como plataforma para a realização das atividades educacionais, atuou satisfatoriamente, mesmo em tempo de crise ou emergência, como estamos passando devido ao COVID 19 (Garcia, Direne, 2013). Outras plataformas tais como; Teams ${ }^{\circledR}$, zoom $^{\circledR}$, Discord ${ }^{\circledR}$, Google meets ${ }^{\circledR}$ foram utilizadas em diversas situações. A plataforma do Microsoft Teams ${ }^{\circledR}$ abrange o Office 365 , não comprometendo a memória do computador ao utilizar o programa. Microsoft (2017). A plataforma zoom tem uma facilidade de agendamento, mas apresenta o incômodo de limitar o tempo de utilização na versão paga, sendo muito procurada como recurso adicional, se a plataforma padrão deixar de funcionar. A plataforma do Discord, muito procurado pelos gamers, pode ser uma opção alternativa, quando o número de usuários é grande. Streamers utilizam canais do Discord para comunicação. Google meats é uma plataforma que segue as demais, no entanto, possui recursos atualizados e facilidades, que as outras não têm, podendo ser considerada como padrão contrapondo ao moodle. Plataformas mais antigas como skype e Hangouts também podem funcionar para aulas remotas, mas não aparecem como opção de trabalho na pesquisa realizada.

O ensino remoto como vem sendo realizado difere do ensino à distância, pelo fato das aulas serem síncronas com verificação de presença durante o período reservado. $O$ ensino híbrido, pode ser definido como, a mistura do ensino online e o presencial de maneira contínua. Aqui são utilizadas as plataformas e as atividades práticas são realizadas na instituição. Esse modelo de ensino fornece autonomia ao aluno que pode buscar conhecimento com outras tecnologias.

\section{ESTRATÉGIAS UTILIZADAS NAS AULAS REMOTAS}

O material existente, quando da adoção de aulas remotas era e ainda é a plataforma de código aberto, moodle. Ela é capaz de prover vários recursos pedagógicos, que vão desde um chat até uma transmissão stream, que foi explorada no início e depois ocorreu uma migração para outras plataformas. A plataforma da Microsoft, Microsoft Teams, oficial, tal qual o moodle, foi bem explorada. A plataforma zoom, pela sua facilidade, também foi muito utilizada para as situações em que a limitação de tempo não fosse importante. Alguns professores adquiriram o zoom para não ter essa restrição. $O$ compartilhamento foi 0 recurso mais difundido, com opção de passa slides. Essa metodologia é mais simples, onde o recurso de escrita auxilia bastante. O problema é que a manipulação com o mouse, deixa o traço desagradável e muito artificial. O compartilhamento com câmara extra foi uma opção para a exposição de aulas ditas on-line, para expor aulas semelhantes às tradicionais, a instituição providenciou câmeras para aqueles professores que solicitaram com antecipação. Outra estratégia foi a utilização de equipamentos tipo touchscreen, com caneta capacitiva, ligado via hypertext transfer protocol (HTTP), com identificação de internet protocol (IP) identificado nos computadores, com aplicativo próprio de escrita em tela. Essa metodologia permite que, por meio de compartilhamento, a aula seja vista em tempo real e com a escrita e conteúdo próprios do docente.

O compartilhamento com outros softwares, como máquinas virtuais ${ }^{1}$, por exemplo Matlab $^{\circledR}$, foi utilizada para suprir algumas aulas práticas. A utilização de segunda câmera para ilustrar experimentos em tempo real, por exemplo, operação de microcontroladores e/ ou circuitos lógicos. Aulas gravadas com experimentos, também foram realizadas e publicadas em concordância com o conteúdo.

1 Máquina virtual (virtual machine) é um programa que simula um ambiente, capaz de executar ou operar em sistemas operacionais e aplicativos, como se fosse uma máquina real (Siqueira, 2010). 


\subsection{Posicionamento de opiniões das estratégias}

O questionamento, com relação ao posicionamento a respeito da solução adotada para o enfrentamento da restrição às aulas presenciais foi a seguinte: Estou elaborando um trabalho e gostaria de saber, minimamente, como é a sua estratégia de aula? Essa pergunta foi enviada via e-mail a docentes escolhidos de forma aleatória nas disciplinas de Cálculo, Física, Programação e disciplinas específicas, características de um curso de engenharia. As respostas também vieram via e-mail, de forma aberta e foram interpretadas de acordo com a resposta. O número de opiniões representa em torno de $10 \%$ do corpo docente da unidade universitária. O quadro 1 sistematiza as opiniões dos docentes e mostra a dimensão dos recursos utilizados.

Quadro 1. Opinião dos professores quanto ao recurso e técnica utilizada

\begin{tabular}{|c|c|c|}
\hline \multirow{4}{*}{ PLATAFORMAS } & moodle & $47 \%$ \\
\hline & zoom & $30 \%$ \\
\hline & teams & $17 \%$ \\
\hline & meets & $6 \%$ \\
\hline $\begin{array}{l}\text { COMPARTILHAMENTO } \\
\text { COM AULAS } \\
\text { SÍNCRONAS }\end{array}$ & \multicolumn{2}{|c|}{$100 \%$} \\
\hline $\begin{array}{l}\text { UTILIZAM MESA } \\
\text { DIGITALIZADORA }\end{array}$ & \multicolumn{2}{|c|}{$30 \%$} \\
\hline $\begin{array}{l}\text { UTILIZAM LOUSA OU } \\
\text { PAINEL PARA } \\
\text { ESCREVER }\end{array}$ & \multicolumn{2}{|c|}{$17 \%$} \\
\hline $\begin{array}{l}\text { SOFTWARES MAIS } \\
\text { UTILIZADOS }\end{array}$ & \multicolumn{2}{|c|}{$\begin{array}{l}\text { POWER POINT } \\
\text { EXCEL } \\
\text { MINITAB } \\
\text { MATLAB e outros }\end{array}$} \\
\hline $\begin{array}{l}\text { UTILIZAÇÃO COM } \\
\text { MAIS DE UMA } \\
\text { CÂMARA }\end{array}$ & \multicolumn{2}{|c|}{$19 \%$} \\
\hline $\begin{array}{l}\text { UTILIZAÇÃO DE } \\
\text { AULAS PRÉ } \\
\text { GRAVADAS }\end{array}$ & \multicolumn{2}{|c|}{$14 \%$} \\
\hline $\begin{array}{l}\text { UTILIZAÇÃO DE } \\
\text { MÁQUINAS VIRTUAIS }\end{array}$ & \multicolumn{2}{|c|}{$6 \%$} \\
\hline
\end{tabular}

Fonte: acervo do autor

\subsection{Posicionamento de opiniões discentes}

O questionamento, com relação ao posicionamento a respeito da solução adotada para o enfrentamento da restrição às aulas presenciais, foi a seguinte: Como está o aprendizado em função das tecnologias adotadas desde o ano de 2020? Essa pergunta foi feita em 4 turmas, de diferentes semestres de um mesmo curso. O universo foi composto por alunos do quarto semestre ao oitavo semestre. As respostas foram diretas com participação coletiva. O número de alunos representa em torno de $6 \%$ do número de alunos do curso. O importante, em detrimento ao cálculo estatístico, foi o externamento de opinião. O quadro 2 sistematiza as opiniões dos discentes.

$\mathrm{Na}$ avaliação dos estudantes o simples "passa, passa" de slides, com ou sem escrita, torna a aula cansativa e por vezes monótonas. Um ponto a ser destacado é a escrita com o mouse, isso desagradou alguns estudantes. Eles se sentiam melhor quando a escrita era realizada por sistemas online com touchscreen e canetas sensíveis. Essa metodologia 
utiliza compartilhamento de tela, com acesso à rede Wi-fi e internet. Isso é possível conectando-se a um endereço IP apresentado pelo aplicativo. Quando a conexão for estabelecida, realiza-se a inclusão de um software de escrita, que, no caso do Samsung é o Samsung notes. Para sistemas IOs, o mesmo princípio é utilizado. Esse processo é mais oneroso, pois depende de um computador (desktop ou laptop) e um tablet, por exemplo. A figura 1 apresenta um sistema com compartilhamento.

O Stream da tela por HTTP permite visualizar a tela do dispositivo no seu navegador da web. Não há necessidade de nenhum software adicional, exceto para este aplicativo e um navegador da web. O aplicativo funciona via WiFi e / ou rede 3G / LTE. Utiliza MJPEG para codificar imagens da tela e enviá-las pela rede. Devido a isso, pode funcionar nos navegadores conhecidos, que suporte MJPEG² (Chrome, EDGE, Firefox).

A quantidade de tarefas, com a atenuante dos estudantes estarem em casa, superou aquelas com aulas presenciais. Isso sobrecarregou os discentes e a devida atenção aos conteúdos foram substituídos por prazos de entrega. A qualidade das aulas foi um ponto de discussão, pois vários fatores podem influenciar. Um deles refere-se à qualidade das redes, ou do equipamento de recepção. Nesse último, assistir a uma aula com um smartphone é extremamente cansativo e descômodo, principalmente quando as aulas têm longa duração. Ainda, dentro desse contexto, a seguridade da energia elétrica e episódios de clima instável, colaboram para a interrupção de conexões, prejudicando a aula e seu conteúdo.

Figura 1. Aspecto de uma configuração de rede local com compartilhamento de tela e software de escrita

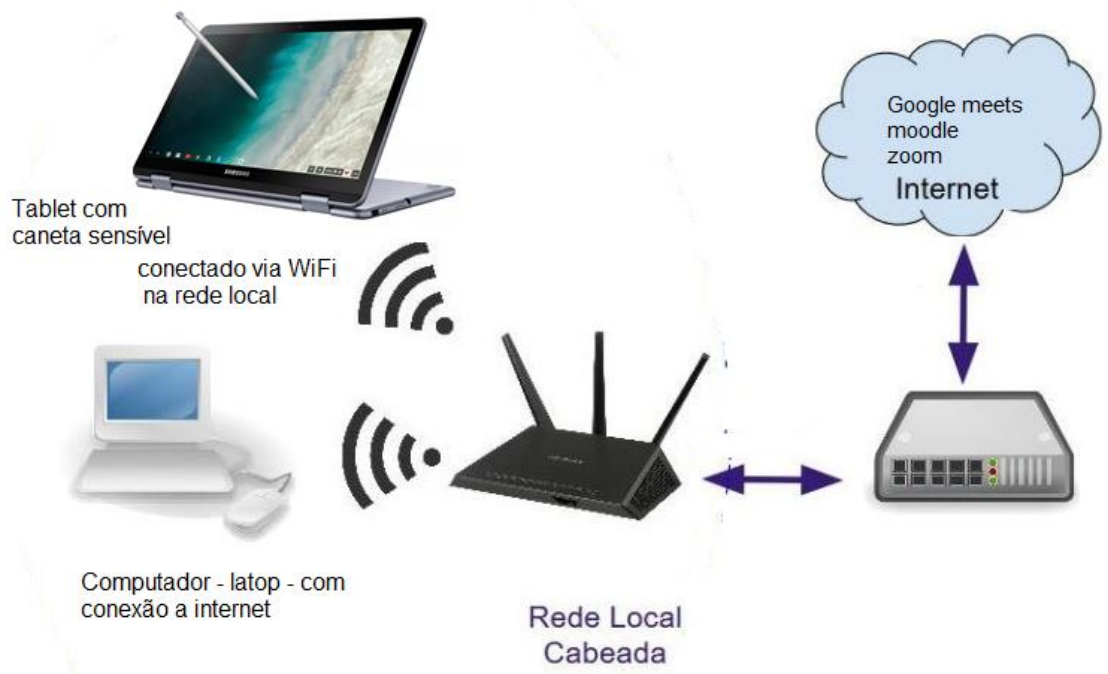

Fonte: Acervo do autor

A situação mais favorável, citada na pergunta livre, é a comodidade do lar e o não enfrentamento do transporte público, ou ao trânsito na ida e retorno da escola. Sem levar

\footnotetext{
${ }^{2}$ Arquivo de vídeo (Moving Picture Experts Group) compactado que utiliza o formato Motion JPEG (M-JPEG ou MJPEG) normalmente criado por câmeras digitais, webcams e outros dispositivos móveis; consiste em uma sequência de.JPEG de imagens. Disponível em: https://en.wikipedia.org/wiki/Motion_JPEG, acesso em 22/04//2021
} 
em consideração a economia dos gastos com a alimentação. As turmas questionadas, quase que de forma unânime, apresentaram esse argumento.

As aulas práticas foram o motivo da desvantagem desse período. Engenharia é fortemente dependente de aulas de laboratório. Para suprir esse problema, várias aulas práticas forma gravadas, respeitando as normas pré-estabelecidas e aos períodos autorizados, para suprir essa necessidade. Aulas dos cursos básicos, física, por exemplo e Metrologia para cursos específicos. No entanto, por mais realista que seja a experiência, nada substitui o toque manual, que, por certo, envolve o cuidado, a segurança, a anotação de dados e outros fatores inerentes à prática. Cita-se, por exemplo, a manipulação de projetor de perfil. Faz parte da análise: o posicionamento correto da peça, a troca de lentes para refino da nitidez e a interpretação da medida. Isso só se realiza estando em loco.

Quadro 2. Opinião dos alunos com relação às tecnologias utilizadas

\begin{tabular}{|c|c|c|c|c|c|c|c|}
\hline TURMA & \multicolumn{2}{|c|}{$\begin{array}{l}\text { 10 questionamento } \\
\text { Qual foi a principal } \\
\text { vantagem do ensino } \\
\text { emergencial? }\end{array}$} & \multicolumn{2}{|c|}{$\begin{array}{c}2^{\circ} \\
\text { questionamento } \\
\text { Qual foi a } \\
\text { principal } \\
\text { desvantagem que } \\
\text { esse período } \\
\text { emergencial } \\
\text { mostrou? }\end{array}$} & \multicolumn{2}{|c|}{$\begin{array}{c}3^{\circ} \text { questionamento } \\
\text { O que mais } \\
\text { desgostou nas aulas } \\
\text { remotas }\end{array}$} & $\begin{array}{c}4^{0} \\
\text { questionamento } \\
\text { A tecnologia de } \\
\text { aulas evoluiu } \\
\text { nesses meses? }\end{array}$ \\
\hline \multirow{3}{*}{$\begin{array}{l}\text { Turma de } \\
4^{\circ} \text { semestre }\end{array}$} & \multirow{3}{*}{$\begin{array}{c}\text { Evitou o } \\
\text { deslocamento } \\
\text { até a } \\
\text { universidade }\end{array}$} & \multirow{3}{*}{$100 \%$} & \multirow{3}{*}{$\begin{array}{l}\text { Ausência } \\
\text { de aulas } \\
\text { práticas } \\
\text { e } \\
\text { convívio }\end{array}$} & \multirow{3}{*}{$100 \%$} & $\begin{array}{c}\text { Passa passa } \\
\text { de slide }\end{array}$ & $60 \%$ & \multirow{3}{*}{$\operatorname{sim}$} \\
\hline & & & & & $\begin{array}{l}\text { Quantidade } \\
\text { de tarefas }\end{array}$ & $80 \%$ & \\
\hline & & & & & $\begin{array}{l}\text { Qualidade } \\
\text { das aulas }\end{array}$ & $20 \%$ & \\
\hline \multirow{3}{*}{$\begin{array}{l}\text { Turma de } \\
7^{\circ} \text { - semestre }\end{array}$} & \multirow{3}{*}{$\begin{array}{c}\text { Evitou o } \\
\text { deslocamento } \\
\text { até a } \\
\text { universidade }\end{array}$} & \multirow{3}{*}{$100 \%$} & \multirow{3}{*}{$\begin{array}{l}\text { Ausência } \\
\text { de aulas } \\
\text { práticas } \\
\text { e } \\
\text { convívio }\end{array}$} & \multirow{3}{*}{$100 \%$} & $\begin{array}{c}\text { Passa passa } \\
\text { de slide }\end{array}$ & $70 \%$ & \multirow{3}{*}{$\operatorname{sim}$} \\
\hline & & & & & $\begin{array}{l}\text { Quantidade } \\
\text { de tarefas }\end{array}$ & $80 \%$ & \\
\hline & & & & & $\begin{array}{l}\text { Qualidade } \\
\text { das aulas }\end{array}$ & $25 \%$ & \\
\hline \multirow{3}{*}{$\begin{array}{l}\text { Turma de } \\
8^{\circ} \text { semestre }\end{array}$} & \multirow{3}{*}{$\begin{array}{c}\text { Evitou o } \\
\text { deslocamento } \\
\text { até a } \\
\text { universidade }\end{array}$} & \multirow{3}{*}{$100 \%$} & \multirow{3}{*}{$\begin{array}{l}\text { Ausência } \\
\text { de aulas } \\
\text { práticas } \\
\text { e } \\
\text { convívio }\end{array}$} & \multirow{3}{*}{$100 \%$} & $\begin{array}{c}\text { Passa passa } \\
\text { de slide }\end{array}$ & $40 \%$ & \multirow{3}{*}{$\operatorname{sim}$} \\
\hline & & & & & $\begin{array}{l}\text { Quantidade } \\
\text { de tarefas }\end{array}$ & $50 \%$ & \\
\hline & & & & & $\begin{array}{l}\text { Qualidade } \\
\text { das aulas }\end{array}$ & $15 \%$ & \\
\hline
\end{tabular}

Fonte: Acervo do autor

Como sabido, Soares et, al (1993), o convívio acadêmico e a proximidade aos Professores, laboratórios, grupos de pesquisa e atividades extracurriculares fazem parte da formação do profissional da engenharia. Os alunos, pelas opiniões, apresentaram essa deficiência como descrédito em aulas remotas. A forma de superar esse defeito seria, colocar aulas práticas no formato presencial, como certamente seria a melhor opinião.

O relato, com relação às tecnologias utilizadas, mostra que houve uma busca para melhorar a qualidade, em termos técnico, das aulas remotas. Segundo professores consultados, houve investimento não só material, como intelectual na busca de cursos e 
capacitação. Situação em que a instituição não se furtou e ofereceu de forma incisiva e constante, atualização em plataformas mais conhecidas.

\section{CONSIDERAÇÕES FINAIS}

As técnicas utilizadas, metodologias e tecnologias, pelo constatado nas opiniões de educadores e alunos indicam que nova mudança está prestes, senão acontecendo, em nossas salas de aulas. O ensino remoto, propiciado pelo contingenciamento, colocou em evidência situações vantajosas, como o estudo no próprio lar e tempo para estudar mais sistemático. Porém, a falta de aulas práticas e falta de convívio, se apresentam como desvantagem ao ensino remoto. Percebe-se uma nova forma de ensino, não como um EaD, ou um curso de plataforma do formato Coursera, mas baseado em aulas online, onde cada aula representa uma aula, ou em outras palavras, "é aquela aula daquela turma", que pode até possuir o mesmo conteúdo em turma diferente, mas não será a mesma aula. Isso difere do EaD, por exemplo.

Perante a essas evidências, se não dizer, facetas, mostram que a hibridissidade do ensino vem a dar um novo rumo ao estado atual.

Uma pesquisa mais profunda e sistemática deverá ser realizada para confrontar a visão de opinião, a qual foi baseado o presente trabalho.

\section{Agradecimentos}

Gostaria de agradecer aos colegas Professores que dispuseram um tempo, para fornecerem dados e técnicas utilizadas em suas aulas, sem eles, certamente não seria possível a realização desse trabalho. Agradeço aos alunos das turmas em que leciono, por tratarem o assunto com seriedade respondendo as questões de maneira clara e objetiva.

\section{REFERÊNCIAS}

BRASIL, DOU. Estabelece normas educacionais excepcionais a serem adotadas durante o estado de calamidade pública reconhecido pelo Decreto Legislativo $n^{\circ}$ 6, de 20 de março de 2020. Edição: 159 | Seção: 1 | Página: 4. Disponível em: https://www.in.gov.br/en/web/dou/-/lei-n-14.040-de-18-de-agosto-de-2020-272981525. Acesso em 02/04/2021

DOU. Lei de Diretrizes e Bases da Educação 23 de dezembro de 1996 - Seção 1 Página 27839, Estabelece as Diretrizes e Bases da Educação Nacional e que foi regulamentada pelo Decreto $n .-5.622$, publicado no D.O.U. de 20/12/05. Disponível em: https://www2.camara.leg.br/legin/fed/decret/2005/decreto-5622-19-dezembro-2005539654-publicacaooriginal-39018-pe.html, acesso em 08/04/2021

BRITO, Jorge Maurício da Silva. A Singularidade Pedagógica do Ensino Híbrido Revista Científica em educação a distância, Rio de janeiro, v. 10 n. 1. 2020 
GARCIA, Fernando Uria. Direne, Alexandre. Metodologia para implementação de estratégias colaborativas mediadas por ferramentas de interação síncrona. Paraná Tecnologias, Sociedade E Conhecimento v. 1 n. 1.2013

MICROSOFT. 5 razões pelas quais o Teams melhora o trabalho em equipe - 2017 . Disponível em:https://news.microsoft.com/pt-br/5-razoes-pelas-quais-o-teams-melhora-otrabalho-em-equipe/. Acesso em 04/04/2021.

OLIVEIRA, Aristóteles da Silva. Pimentel, Fernando Sílvio Cavalcante. Mercado, Luís Paulo Leopolodo. Campos, Tatiane. Mundos Virtuais e educação: desafios e possibilidades, Revista Multilíngue - UFSCar. v.7, n.2. 2013

RUSHKOFF, Douglas, Team Human, Editors W. W. Norton \& Company, New York, 2019

SIQUEIRA, Luciano Antonio. Máquinas virtuais com VitualBox. ed. Linux New Media do Brasil Ltda, São Paulo, 2010

SOARES, adriana benevides. FRANCISCHETTO, vanuza. DUTRA, Betânia marques. MIRANDA, Jacqueline Maia de. NOGUEIRA, Cátia c. De c. Leme, Vanessa r. ARAÚJO, Alexandra m. ALMEIDA, Leandro. O impacto das expectativas na adaptação acadêmica dos estudantes no ensino superior. psico-usf. Itatiba, v.19, n.1, 2014

STAKER, Heather. Horn, Michael B. Usando a Inovação Disruptiva para Aprimorar a Educação. ed. Penso. Porto Alegre. 2015.

\section{TEACHING CHALLENGES AND TECHNOLOGICAL TOOLS IN NON PRESENSIALITY.}

\section{Abstract:}

The creativity and agility of teachers in this emergency period had a fundamental help, the platforms of learning systems, they were and are responsible for keeping the teacher student contact minimally active. This kept the school working. However, it should be noted that the quality and robustness of these activities is due to the technical and administrative sector of educational institutions. The present work presents a collection and diversity of actions taken by teachers, their methodologies and techniques to maintain the contents as established in teaching plans. The use of slides and screen sharing was prevalent and had a positive impact among students. The testimonies and the collection of techniques had the participation of teachers and students from the areas of basic and specific cycle. It was noticed that the simplicity of the use of sophisticated techniques prevailed during the observation period, which happened between 2020 until today. The synchronous standard was adopted for the theoretical classes and, when allowed, face-to-face laboratory classes, thus characterizing a hybrid teaching. A total of $15 \%$ of teachers were heard from a total of 130 and opinions from 100 students in classes from different stages of the same course. 
Key words: Hybrid teaching, Synchronous activities, Remote teaching 